\title{
An unfrozen water retention curve for capturing soil density and specific surface effects
}

\author{
Jiwen Zhang ${ }^{1,2,3^{*}}$, Qingyi $\mathrm{Mu}^{1, *}$, Hongjian $\mathrm{Liao}^{1}$ and Jie $\mathrm{Cao}^{2,3}$ \\ ${ }^{1} \mathrm{Xi}$ 'an Jiaotong University, Department of Civil Engineering, $710049 \mathrm{Xi}$ 'an Shanxi, China \\ ${ }^{2}$ JIKAN Research Institute of Engineering Investigations and Design, Co., Ltd, 710043 Xi'an Shanxi, China \\ ${ }^{3}$ Shaanxi Key Laboratory for the Property and Treatment of Special Soil and Rock, 710043 Xi' an Shanxi, China
}

\begin{abstract}
Unfrozen water retention curve (UWRC) defines the relationship between temperature and unfrozen water content in frozen soils. Although many models have been proposed for the UWRC, these existing models cannot predict UWRC well over a wide temperatures range. In this study, a new UWRC model is proposed with explicit considerations of both capillarity and adsorption. In this model, capillarity is considered dominating when the freezing of soil pore water at higher temperatures (above $-2^{\circ} \mathrm{C}$ ), whereas the effects of adsorption pronounce at temperatures below $-2^{\circ} \mathrm{C}$. Moreover, effects of void ratio on the freezing of capillary water are incorporated. The proposed model was applied to predict UWRCs of silt and clay at different initial void ratios over a wide temperature range (from -50 to $0^{\circ} \mathrm{C}$ ). Predicted results by this new model are compared with predictions by three well-known existing models. The new model can capture the density effects on UWRC. Moreover, the new model can predict better UWRC over a wide temperature range since it explicitly considers both effects of capillarity and adsorption.
\end{abstract}

\section{Introduction}

For solute-free soil, the capillarity and adsorption are the two distinct mechanisms controlling the entire freezing of pore water [1]. Unfrozen water retention curve (UWRC), defining the relationship between temperature and unfrozen water content, is an important soil property for calculating frost heave and thawing settlement [2-4]. Many semi-empirical models were proposed for UWRC based on experimental data. Anderson and Tice [5] found that UWRC can be approximated as a power equation as follows:

$$
\theta_{w}=\frac{p_{d}\left(1-\theta_{s}\right)}{100 p_{w}} \alpha(-T)^{\beta}
$$

where $\theta_{\mathrm{w}}$ is the unfrozen volumetric water content; $\mathrm{T}$ is the soil temperature $\left({ }^{\circ} \mathrm{C}\right) ; \alpha$ and $\beta$ are soil parameters which are related to specific surface area or liquid limit; $\mathrm{p}_{\mathrm{d}}$ and $\mathrm{p}_{\mathrm{w}}$ are the soil dry density and water density respectively and $\theta_{\mathrm{s}}$ is the saturated volumetric water content. Equation (1) is formulated on the assumption that the adsorptive rather than capillary force governs the freezing of pore water. On the other hand, the exponential equation was also widely used for UWRC [6]:

$$
\theta_{w}=\theta_{r e s}+\left(\theta_{s}-\theta_{r e s}\right) \exp \left(\alpha_{1} T\right)
$$

where $\theta_{\text {res }}$ represents the residual volumetric water content; $\alpha_{1}$ is a soil parameter defining the freezing rate of pore water. The freezing of residual water is ignored in this model.
Alternatively, some UWRC models have been developed on the basis of soil water retention models and the Clausius-Clapeyron equation. The water retention curve proposed by van-Genuchten [7] was used by Nishimura et al. [8]:

$$
\theta_{w}=\left[1+\left(\frac{\lambda p_{w} \ln ((\mathrm{T}+273.15) / 273.15)}{\alpha_{0}}\right)^{n_{0}}\right]^{-m_{0}}
$$

where $\alpha_{0}, \mathrm{n}_{0}$ and $\mathrm{m}_{0}$ are soil parameters and $\lambda$ is the latent heat of fusion of water $\left(333.7 \mathrm{~kJ} \mathrm{~kg}^{-1}\right.$ at $\left.0^{\circ} \mathrm{C}\right)$. In addition, the Fredlund and Xing equation [9] were also proposed to formulate the UWRC. However, these models may not give a well calculation for the UWRC over a wide range of temperatures as the lack of considerations of both capillarity and adsorption. Moreover, effects of initial void ratio, which significantly influences the capillarity [9-10], on UWRC was not explicitly considered in these models.

A new UWRC model is proposed, which separates the freezing of capillary and adsorbed water. An existing water retention curve equation is extended for modelling the freezing of capillary water at different void ratios, and a new equation is proposed for the freezing of adsorbed water. The drying branch of the water retention curve was used to combine the Clausius-Clapeyron equation. It is mainly because that the concept of soil freezing process is like that of the drying of unsaturated soils except that ice is substituted by air, air being intruded into the soil pores. Extensive experimental results reported in the literature are used to verify the new model. The prediction by the new model is compared with those of equation (1) through (3). 


\section{Development of a new UWRC model}

\subsection{Clausius-Clapeyron equation}

In a closed system, the phase equilibrium between ice and unfrozen water can be described through the Clausius-Clapeyron equation. The phase equilibrium includes mechanical equilibrium (ice and unfrozen water at identical pressure), thermal equilibrium (ice and unfrozen water at identical temperature) and chemical equilibrium (ice and unfrozen water at identical chemical potential). According to Nishimura et al. [8], the Clausius-Clapeyron equation can be expressed as:

$$
d u_{w} / p_{w}-d u_{i} / p_{i}=\lambda /(T+273.15) d T
$$

where $u_{w}$ and $u_{i}$ are water and ice pressure, respectively; $\mathrm{p}_{\mathrm{w}}$ and $\mathrm{p}_{\mathrm{i}}$ are water and ice density, respectively; $\lambda$ is latent heat of fusion of water $\left(333.7 \mathrm{~kJ} \mathrm{~kg}^{-1}\right.$ at $\left.0^{\circ} \mathrm{C}\right)$ and $\mathrm{T}$ is temperature $\left({ }^{\circ} \mathrm{C}\right)$. The integral form of equation (4) is:

$$
u_{w} / p_{w}-u_{i} / p_{i}=\int_{0}^{T} \lambda /(T+273.15) d T
$$

The value of $\lambda$ is assumed to be temperature independent and the ice pressure is zero with reference to atmospheric pressure [1]. Equation (5) can be simplified as:

$$
u_{w}=p_{w} \lambda \ln (T+273.15) / 273.15
$$

It should be noted that the pore water pressure calculated by equation (6) is a negative value as the soil temperature is below zero. In frozen soil, the difference between ice pressure and water pressure is defined as the cryogenic suction [11]. As the ice phase is assumed to be at the atmospheric pressure, the cryogenic suction is equal to the negative pore water pressure.

$$
s=-u_{w}
$$

Therefore, the relationship between cryogenic suction and soil temperature could be obtained by substituting equation (7) into equation (6):

$$
s=-p_{w} \lambda \ln (T+273.15) / 273.15
$$

For equation (8), the cryogenic suction increases with a decrease in soil temperature. The development of cryogenic suction reduces the potential of pore water and hence the water could retain liquid state in soil pores. In addition, the osmotic suction is ignored in equation (8). Similar to unsaturated soils, capillarity and adsorption are two distinct physical mechanisms governing the development of soil cryogenic suction [1]. The capillarity occurs due to the presence of a curved icewater interface. The adsorption of water is attributed to the presence of exchangeable cation hydration, mineral surface, or crystal interlayer surface hydration [12].

Figure 1 shows the idealized freezing process of pore water in solute-free saturated soil. The soil specimen consists of soil particle and pore water (capillary and adsorbed water) at the initial state. With a decrease in soil temperature, the phase change firstly occurs in the capillary water which is located relatively far from the soil particle surfaces. The soil pore size distribution, which influences the development of capillary force, is expected to play an important role for the freezing of capillary water. With the temperature further decreases, only a small portion of capillary water which is located in the small pores and the corners of particles retain liquid state. According to the Young-Laplace equation, the water in these small pores could develop high capillary forces and hence retain liquid state at low temperatures. On the other hand, some of the adsorbed water also starts to be frozen in this stage. At the third stage, the phase change occurs in the adsorbed water which surrounds around soil particles. The freezing of absorbed water is influenced by the specific surface area, which control the development of adsorptive forces [17].

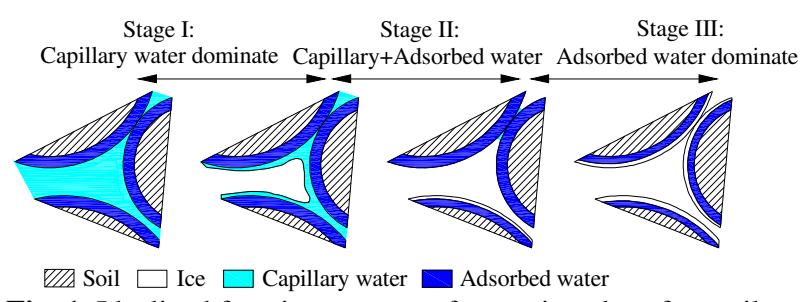

Fig. 1. Idealized freezing process of water in solute-free soil

\subsection{Freezing of capillary water}

The freezing of capillary water, which is governed by capillary force, is dependent on the soil pore size distribution. In this study, the initial void ratio is selected as a parameter to represent the average pore size. Gallipoli et al. [13] proposed an equation to describe the relationship between water content and suction. The equation incorporates the effects of initial void ratio on the volumetric water content at different suctions.

$$
\theta_{w}=\left[1 /\left(1+\left(m_{0} e^{m_{1}} s\right)^{m_{2}}\right)\right]^{m_{3}}
$$

where $\theta_{\mathrm{w}}$ is the volumetric water content; e is the initial void ratio; $s$ is the suction and $\mathrm{m}_{0}, \mathrm{~m}_{1}, \mathrm{~m}_{2}$ and $\mathrm{m}_{3}$ are soil parameters. It should be noted that the capillary and adsorbed water were not separated in equation (9). In this study, equation (9) is modified and adopted to represent the freezing of capillary water as follows:

$$
\theta_{c w}=\left(\theta_{s}-\theta_{a \max }\right)\left[1+\left(m_{0} e^{m_{1}} s\right)^{m_{2}}\right]^{m_{3}}
$$

where $\theta_{\mathrm{cw}}$ is the volumetric capillary water content; $\theta_{\mathrm{s}}$ is the saturated volumetric water content and $\theta_{\text {amax }}$ is the maximum volumetric adsorbed water content. The freezing of capillary water could be achieved by substituting equation (8) into equation (10):

$$
\begin{aligned}
& \theta_{c w}=\left(\theta_{s}-\theta_{a \max }\right)\left[1 /\left(1+\left(m_{0} e^{m_{1}} s\right)^{m_{2}}\right)\right]^{m_{3}}=\left(\theta_{s}-\theta_{a \max }\right) \\
& \cdots \cdots \cdot\left\{1 /\left[1+\left(m_{0} e^{m_{1}} p_{w} \lambda \ln ((\mathrm{T}+273.15) / 273.15)\right)^{m_{2}}\right\}^{m_{3}}\right.
\end{aligned}
$$

Previous studies [7] suggested that the water content at a suction of $1500 \mathrm{k} \mathrm{Pa}$ could be used as the residual water content. In this study, the maximum adsorbed water content is determined as the same method as that 
of residual water content [14]. A suction of $1500 \mathrm{kPa}$ is converted to a temperature about $-2^{\circ} \mathrm{C}$ based on equation (8). Therefore, the value of parameter $\theta_{\text {amax }}$ could be determined as the unfrozen volumetric water content at a temperature of $-2^{\circ} \mathrm{C}$.

\subsection{Freezing of adsorbed water}

The freezing of soil pore water at low temperature ranges $\left(<-2^{\circ} \mathrm{C}\right)$ occurs in the adsorbed water. Previous studies $^{[1]}$ showed that the UWRC at the low temperature range has a good agreement with the water retention curve by converting temperature to soil suction through Clausius-Clapeyron equation. $\mathrm{Lu}$ [14] proposed an exponential equation to describe the water retention characteristic of absorbed water. In this study, a similar exponential equation is adopted for the freezing of adsorbed water.

$$
\theta_{a w}=\theta_{\text {a max }}\left\{1-\left[\exp \left(\left(T-T_{\min }\right) / T\right)\right]^{k}\right\}
$$

where $T_{\min }$ is the temperature that all the pore water is frozen and $\mathrm{k}$ is a soil parameter defining the freezing rate of adsorbed water. According to previous study [15], there is a maximum suction about $10^{6} \mathrm{kPa}$ corresponding to a zero water content in any porous medium. The maximum matric suction could be converted to a minimum temperature of $-259^{\circ} \mathrm{C}$ according to equation (8). Therefore, the parameter of $\mathrm{T}_{\min }$ in equation (12) is determined as $-259^{\circ} \mathrm{C}$.

\subsection{The new UWRC model}

By combining equation (11) and (12), the total amount of unfrozen water under a given soil temperature could be expressed as:

$$
\begin{aligned}
& \theta=\theta_{c w}+\theta_{a w} \\
& =\left(\theta_{s}-\theta_{\text {amax }}\right)\left\{1 /\left[1+\left(m_{0} e^{m_{1}} p_{w} \lambda \ln ((\mathrm{T}+273.17) / 273.15)\right)^{m_{2}}\right]\right\}^{m_{3}} \\
& +\theta_{\text {a } \max }\left\{1-\left[\exp \left(\left(T-T_{\min }\right) / T\right)\right]^{k}\right\}
\end{aligned}
$$

In this equation, five fitting parameters including $\mathrm{m}_{0}$, $\mathrm{m}_{1}, \mathrm{~m}_{2}, \mathrm{~m}_{3}$ and $\mathrm{k}$ are included. Furthermore, the parameter $\mathrm{k}$ is suggested to be ranged from 0.02 to 0.04 , as explained in the "2.4 Freezing of adsorbed water".

\section{Verification of the new UWRC model}

\subsection{UWRCs of silt at different void ratios}

Azmatch et al. [9] measured the UWRC of Devon Silt at three different initial void ratios. The soil tested is with a specific gravity of 2.65 , a clay fraction of $25 \%$ and a silt fraction of $75 \%$. Slurry of the soil is prepared and then consolidated under different stresses (50, 100 and 400 $\mathrm{kPa}$ ). The UWRC is measured with the soil specimens unloaded to a zero stress condition. The initial void ratio of these three specimens is determined as $0.61,0.58$ and 0.55 , respectively.

Fig. 2 shows the comparisons between the measured and calculated UWRCs of the soil specimen at different initial void ratios. For the measured UWRCs, the unfrozen water content decreases with a decrease in soil temperature. Furthermore, the freezing rate of pore water decreases with a decrease in soil void ratio. During the phase change, more water could be retained liquid state under a given temperature in the soil specimen with a smaller void ratio (0.55). Similar experimental results were observed by Konard [10] showing that the unfrozen water retention capacity increases with decreasing of soil void ratio. It is because that the capillary water in small pores results in high capillary forces than that of the water in large pores and hence could retain liquid state at low temperatures. It should be noted that the measured soil UWRCs [9] at void ratios of 0.58 and 0.55 have some cross points when temperatures are smaller than -2 ${ }^{\circ} \mathrm{C}$. It is probably due to experimental errors, considering the difficulties in the accurate measurement of unfrozen water content. To explore the capability of the new model, equation (13) was applied to calculate the UWRC of soil specimen at different initial void ratios. The parameters of $\mathrm{m} 0, \mathrm{~m} 1, \mathrm{~m} 2, \mathrm{~m} 3$ and $\mathrm{k}$ were obtained by three-dimensional least-square fitting in $\theta: \mathrm{T}:$ e space with the measured UWRCs at the initial void ratio of 0.61 and 0.55 . The same parameters were used to calculate the UWRC at the initial void ratio of 0.58 . The proposed model has a high value of $\mathrm{R}^{2}(0.93)$ for the calibration of model parameters. Moreover, equation (13) provides a reasonably good calculation of the UWRC at the initial void ratio of 0.58 through the calibrated parameters. On the other hand, the calculation of unfrozen absorbed water content for the three soil specimens is exactly the same. According to the new model, the increase of unfrozen water retention capacity with decreasing void ratio is mainly contributed by the unfrozen capillary water but not the adsorbed water.

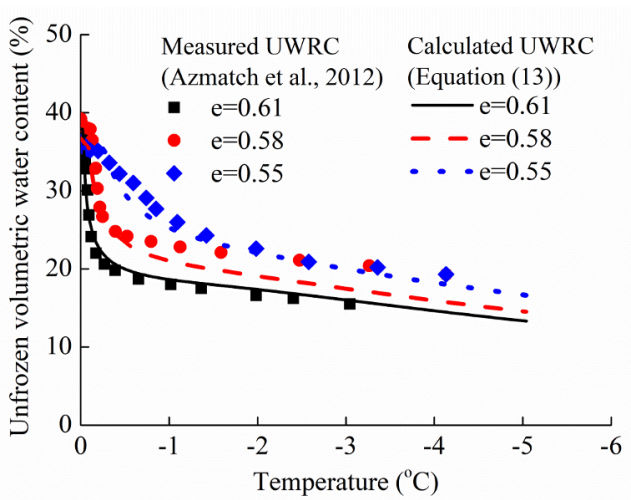

Fig. 2. Comparisons between the measured and calculated UWRCs of silt with different initial void ratios.

\subsection{UWRC of clay over a wide temperature range}

Yoshikawa and Overduin [16] measured the UWRC of Umiat bentonite with different commercial sensors including time domain reflectometry, nuclear magnetic resonance, and frequency domain reflectometry sensor. The measured UWRCs cover a wide temperature range from -50 to $0^{\circ} \mathrm{C}$. In this part, the new model was used to calculate the UWRC of Umiat bentonite over a wide range of temperatures. In addition, as the UWRC under a 
given initial void ratio was calculated in this section, the parameter of $\mathrm{m} 1$ in the new model which represents the effects of void ratio on UWRC was set to zero. On the other hand, three popular existing models found in the literature (equation (1) through (3)) were adopted to calculate the UWRCs for comparisons.

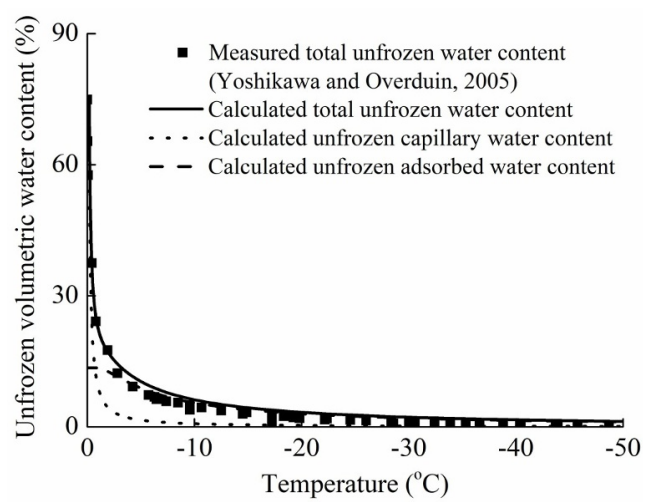

(a)

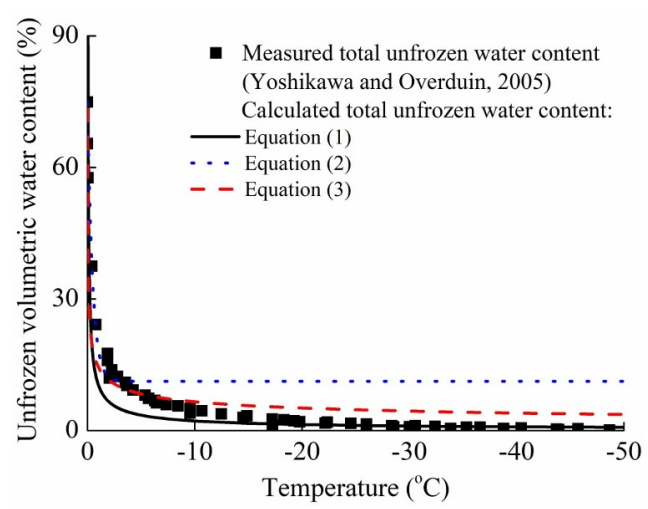

(b)

Fig. 3. Comparisons between the measured and calculated UWRCs of clay over a wide range of temperatures: (a) the new model; (b) the existing models.

Figure 3(a) shows the comparisons between the measured and calculated UWRCs over a wide temperature range with the new model. The unfrozen capillary and adsorbed water, which are calculated by equation (11) and equation (12) respectively, are shown in the figure. The aim is to further understand the influence of capillarity and adoption on water freezing. The soil parameter of $\mathrm{m}_{0}, \mathrm{~m}_{1}, \mathrm{~m}_{2}, \mathrm{~m}_{3}$ and $\mathrm{k}$ are $4.62 \times 10^{-}$ ${ }^{3}, 0,73.577,0.015$ and 0.021 respectively. The parameter of $\theta_{\operatorname{amax}}$ is determined as $13.5 \%$. The proposed model has a high value of R2 (0.97). The well performance is mainly because the freezing of capillary and adsorbed water is differentiated. The entire freezing process of pore water, which includes both capillarity and adsorption, could be well captured. On the other hand, with soil temperature decreasing from 0 to $-2^{\circ} \mathrm{C}$, the unfrozen capillary water content decrease significantly while the unfrozen adsorbed water content almost keeps constant. It shows that the phase change is dominated by capillary water. With the soil temperature further decreasing from -2 to $-10^{\circ} \mathrm{C}$, the unfrozen capillary water content continues to decrease but with much smaller rates than that in the temperature ranging from -2 to $0^{\circ} \mathrm{C}$.
On the other hand, the adsorbed water also starts to be frozen in this stage. It shows that the phase change occurs in both capillary and adsorbed water. With the soil temperature below $-10^{\circ} \mathrm{C}$, the unfrozen capillary water content is almost zero and the UWRC is consistent with the freezing curve of adsorbed water. It shows that the phase change dominates by the adsorbed water.

Figure 3(b) shows the comparisons between the measured and calculated UWRCs with existing models. For the power equation, an overall poor performance was obtained with a low value of $R^{2}(0.7)$. The calculated UWRC shows significant discrepancies at the high temperature range $\left(>-10^{\circ} \mathrm{C}\right)$ while a good agreement was obtained with the soil temperature ranging from -50 to $-10^{\circ} \mathrm{C}$. On the other hand, the exponential equation also has a low value of $R^{2}(0.72)$. The calculated UWRC by exponential equation agrees well with the measured UWRC with soil temperature ranging from -2 to $0^{\circ} \mathrm{C}$. However, the calculated UWRC almost flats with the soil temperature below $-2^{\circ} \mathrm{C}$. It is because that the freezing of adsorbed water, which dominates the phase change at the low temperature range, is ignored in the exponential equation. Significant discrepancies were induced between the calculated and measured UWRCs. It can be seen that both the power and exponential equations have poor performance for calculating the UWRC over a wide range of temperatures. For the v-G equation, the value of $\mathrm{R}^{2}$ is 0.9 which is about $8 \%$ smaller than that of the new model.

\subsection{UWRCs of soil with different specific surface areas}

Hivon and Sego [17] measured the UWRC of three soil types through the time domain reflectometry method. Each of soil has a different grain size distribution: soil-A, which is a very fine silty sand called Devon silt; a silty sand referred to as soil-B, obtained by mixing $50 \%$ of soil-A and $50 \%$ of soil-C and a sand referred to as soil C. It should be noted that the specific surface area of soil-A is the largest among these three soils. In addition, as the UWRC under a given initial void ratio was calculated in this section, the parameter of $\mathrm{m}_{1}$ in the new model which represents the effects of void ratio on UWRC was set to zero. The three popular existing models found in the literature (equation (1) through (3)) were also adopted to calculate the UWRC for comparison.

\section{Soil-A: Fine silt sand}

Figure 4(a) shows comparisons between the measured and calculated UWRCs of fine silt sand with the new model. The freezing of capillary water and adsorbed water, which is calculated by equation (11) and (12) respectively, is shown in the figure. The soil parameter of $\mathrm{m}_{0}, \mathrm{~m}_{1}, \mathrm{~m}_{2}, \mathrm{~m}_{3}$ and $\mathrm{k}$ are $3.33 \times 10^{-3}, 0$, $63.347,0.022$ and 0.025 , respectively. The value of $\theta_{\operatorname{amax}}$ is determined as $8.89 \%$. It can be seen that the UWRC calculated by the new model has a high value of $\mathrm{R}^{2}$ (0.97). According to the calculation, the phase change mainly occurs in the capillary water with soil temperature decreasing from 0 to $-2^{\circ} \mathrm{C}$. A transition 
regime which includes the freezing of both capillary and adsorbed water is exhibited with soil temperature further decreasing from -2 to $-4^{\circ} \mathrm{C}$. With the soil temperature below $-4^{\circ} \mathrm{C}$, the variation of unfrozen volumetric water content is consistent with the freezing curve of adsorbed water. It shows that the phase change only occurs in the absorbed water.

Figure 4(b) shows the comparisons between the measured and calculated UWRC of fine silt sand with existing models. It can be seen that the power equation shows a low value of $\mathrm{R}^{2}(0.87)$ indicating a poor performance for calculating the UWRC of fine silt sand. For the exponential equation, the value of $\mathrm{R}^{2}$ is 0.88 which is similar to that of the power equation. The value of $\mathrm{R}^{2}$ for power equation and exponential equation is about $11 \%$ lower than that of the new model. Furthermore, the exponential equation provides a good calculation with the soil temperature above $-2^{\circ} \mathrm{C}$ while significant discrepancies were exhibited as the soil temperature is below $-2^{\circ} \mathrm{C}$. It is mainly because the freezing of adsorbed water is ignored in the exponential equation as explained in the section of "UWRC of clay over a wide temperature range". On the other hand, the $\mathrm{v}-\mathrm{G}$ equation well calculates the UWRC of fine silt sand, as proved by a relatively high value of $R^{2}(0.96)$.

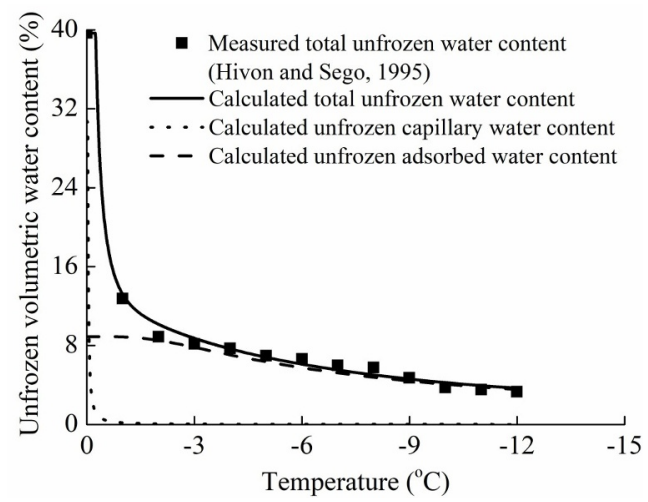

(a)

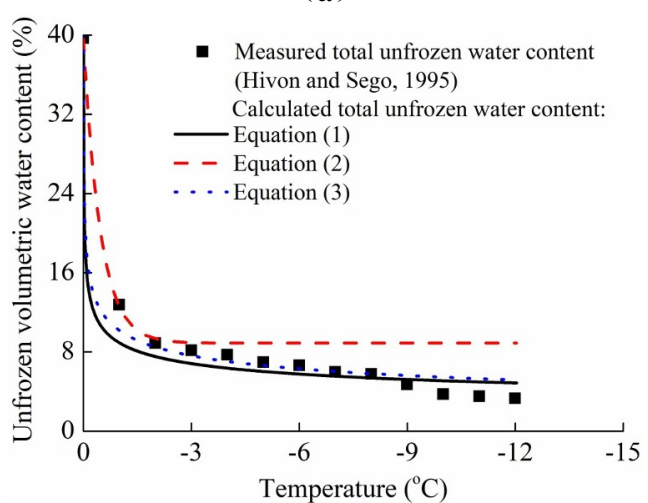

(b)

Fig. 4. Comparisons between the measured and calculated UWRCs of fine silt sand: (a) the new model; (b) the existing models.

\section{Soil-B: Silt sand}

Figure 5(a) shows comparisons between the measured and calculated UWRC of silt sand with the new model. The soil parameter of $\mathrm{m}_{0}, \mathrm{~m}_{1}, \mathrm{~m}_{2}, \mathrm{~m}_{3}$ and $\mathrm{k}$ are $6.5 \times 10^{-3}, 0,69.978,0.018$ and 0.026 , respectively.
The value of $\theta_{\mathrm{amax}}$ is determined as $3.91 \%$. The value of $\theta_{\text {amax }}$ for silty sand is $57.14 \%$ smaller than that of fine silt sand. It is because that the specific surface area of fine silt sand is larger than that of silt sand. Furthermore, a high value of $R^{2}(0.98)$ is obtained for the calculated UWRC with the new model.

Figure 5(b) shows the comparisons between the measured and calculated UWRCs of silt sand with existing models. For the power equation, a high value of $\mathrm{R}^{2}(0.98)$ is obtained. On the other hand, the exponential equation also performs well for calculating the UWRC of silt sand $\left(\mathrm{R}^{2}=0.98\right)$. It is mainly because silt sand has a small specific area and hence a low value of $\theta_{\text {res }}(3.91 \%)$. The discrepancy between the measured and calculated UWRCs which is caused by freezing of adsorbed water is insignificant. In addition, $\mathrm{v}-\mathrm{G}$ equation shows a similar value of $R^{2}(0.98)$ to that of power and exponential equations. It can be seen that all power equation, exponential equation and $\mathrm{v}-\mathrm{G}$ equation have good calculations for the UWRC of silt sand which has a relatively small value of specific surface area.

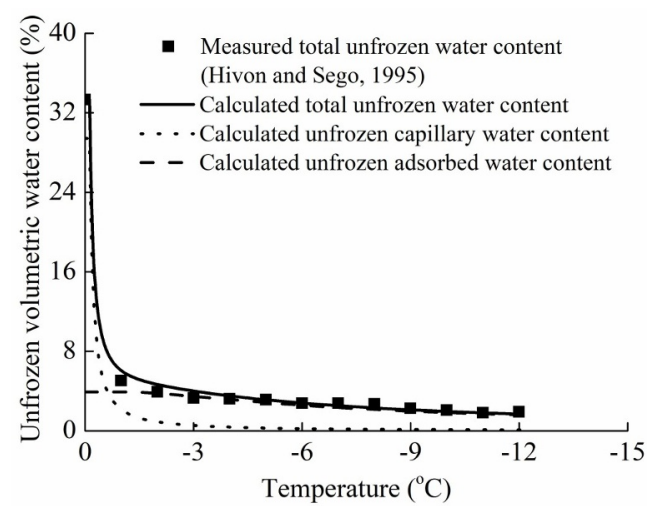

(a)

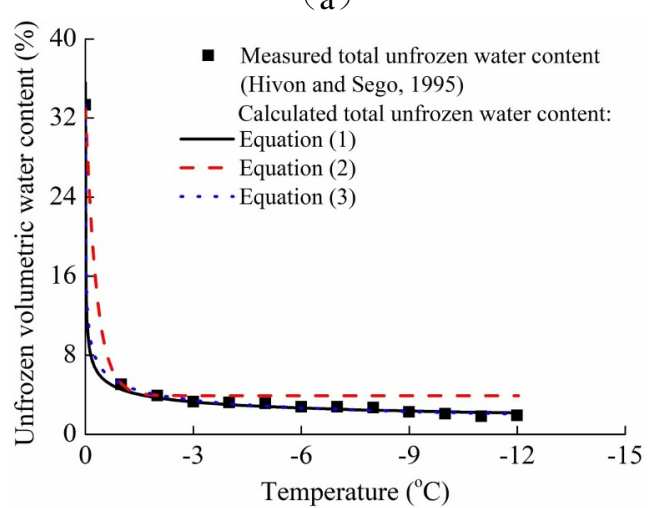

(b)

Fig. 5. Comparisons between the measured and calculated UWRCs of silt sand: (a) the new model; (b) the existing models.

\section{Soil-C: Sand}

Figure 6(a) shows the comparisons between the measured and calculated UWRCs of sand with the new model. As the adsorbed water content is negligible $\left(\theta_{\mathrm{amax}}=0\right)$ for sand, the parameter of $\mathrm{k}$ is equal to zero and the proposed new model is identical as the $\mathrm{v}-\mathrm{G}$ equation. It shows that the freezing of pore water in sand is only dominated by the capillarity. The soil parameter of $\mathrm{m}_{0}$, $\mathrm{m}_{1}, \mathrm{~m}_{2}$ and $\mathrm{m}_{3}$ are equal to $0.79,0,73.949$ and 0.008 , 
respectively. As expected, a high value of $R^{2}$ (1) is achieved. Figure 6(b) shows the comparisons between the measured and calculated UWRCs of sand with existing models. All power equation, exponential equation and $v-G$ equation have high value of $R^{2}(1)$.

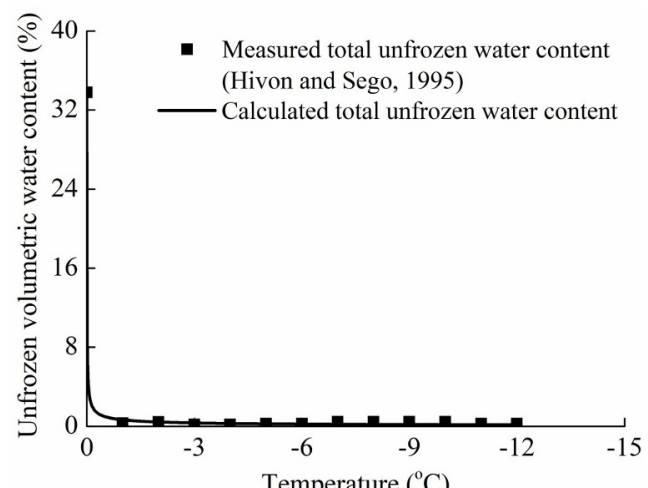

(a)

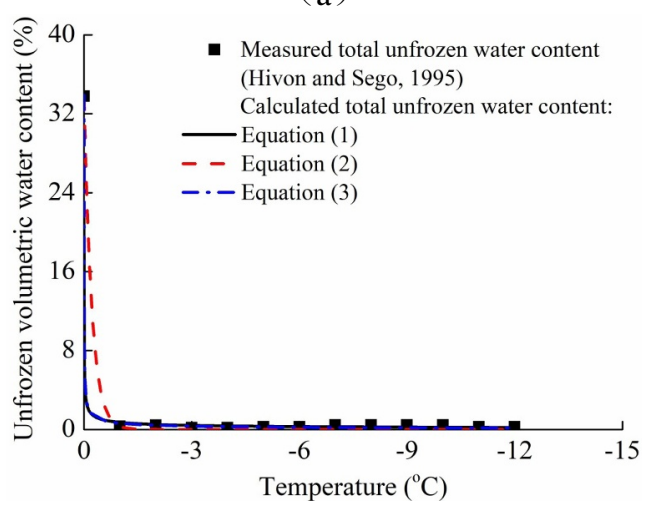

(b)

Fig. 6. Comparisons between the measured and calculated UWRCs of sand: (a) the new model; (b) the existing models.

The comparisons shown in Figure 4-6 demonstrate that the proposed new model improves the performance for calculating the UWRC of soil with a large specific area such as fine silt sand (see Figure 4). It is mainly because both capillarity and adsorption contribute to the freezing of pore water in fine silt sand. A better performance was obtained for the new model which explicitly separates the freezing of capillary and adsorbed water. In addition, the proposed new equation has a similar performance with the power equation, exponential equation and $\mathrm{v}-\mathrm{G}$ equation for calculating the UWRC of the soil with relative small specific surface area such as silt sand (see Figure 5) and sand (see Figure 6 ). For the silt sand and sand, the freezing of pore water is dominated by capillarity.

\section{Summary and conclusions}

In this study, a new UWRC model is developed by differentiating the freezing of capillary and adsorbed water. Capillarity and adsorption is considered dominating when the freezing of pore water at higher (above $-2^{\circ} \mathrm{C}$ ) and lower temperatures (below $-2^{\circ} \mathrm{C}$ ), respectively. Moreover, effects of initial void ratio on the freezing of capillary water are explicitly incorporated.

The new model and three existing models are applied to simulate UWRCs of various soils. It is evident that the new model improves the calculation of unfrozen water content under a wide temperature range (from -50 to $0^{\circ} \mathrm{C}$ ) over existing models. This improvement is attributed to explicit considerations of capillarity and adsorption. Furthermore, only the new model is able to capture effects of initial void ratio on UWRC.

\section{Acknowledgement}

This work was supported by the National Science Foundation of China (51909205), the Science and Technology Coordination and Innovation Project of Shaanxi Province in China (2016KTZDSF03-02) National Key Research and Development Program of China (2017YFD0800501), the innovative talents promotion plan in Shaanxi Province of China (2018KJXX-033), Chinese Postdoctoral Science Foundation (2018M631166) and the Fundamental Research Funds for the Central Universities of China (xjj2018250).

\section{References}

1. M. Lebeau, J.M. Konrad, Water. Resour. Res Water Resources Research., 48(7), W07523 (2012)

2. D.C. Sheng, S. Zhang, F.J. Niu, G. Cheng, Géotechnique, 64(2), 144-154 (2014)

3. S. Zhang, D.C. Sheng, G. Zhao, F.J. Niu, Z. He, Can Geotech. J., 53(3), 520-529 (2015)

4. Y. Zhang, R.L. Michalowski, J. Geotech. Geoenviron. Eng., 141(7), 04015027 (2015)

5. D.M. Anderson, A.R. Tice, Highway. Res. Rec., 393, 12-18 (1972)

6. R.L. Michalowski, Cold. Reg. Sci. Technol., 22(1), 47-63 (2015)

7. M.T. Van Genuchten, Soil. Sci. Soc. Am. J., 44(5), 892-898 (1980)

8. S. Nishimura, A. Gens, S. Olivella, R.J. Jardine, Géotechnique, 59(3), 159-171 (2009).

9. T.F. Azmatch, D.C. Sego, L.U. Arenson, K.W. Biggar, Cold. Reg. Sci. Technol., 83, 103-109 (2012).

10. J.M. Konrad, Cold. Reg. Sci. Technol., 18(1), 49-55 (1990)

11. H.R. Thomas, P.J. Cleall, Y.C. Li, C. Harris, M. Kern-Luetschg, Géotechnique, 59(3), 173-184 (2009)

12. M. Tuller, D. Or, L.M., Dudley, Water. Resour. Res., 35(7), 1949-1964 (1999).

13. D. Gallipoli, A. Gens, R. Sharma, J. Vaunat, Géotechnique, 53(1), 123-136 (2003).

14. N. Lu, J. Geotech. Geoenviron., 142(10), 04016051 (2016).

15. D.G. Fredlund, A. Xing, Can Geotech. J., 31(4), 521-532 (1994).

16. K. Yoshikawa, P.P. Overduin, Cold. Reg. Sci. Technol., 42(3), 250-256 (2005).

17. E.G. Hivon, D.C. Sego, Can Geotech. J., 32(2), 336-354 (1995). 